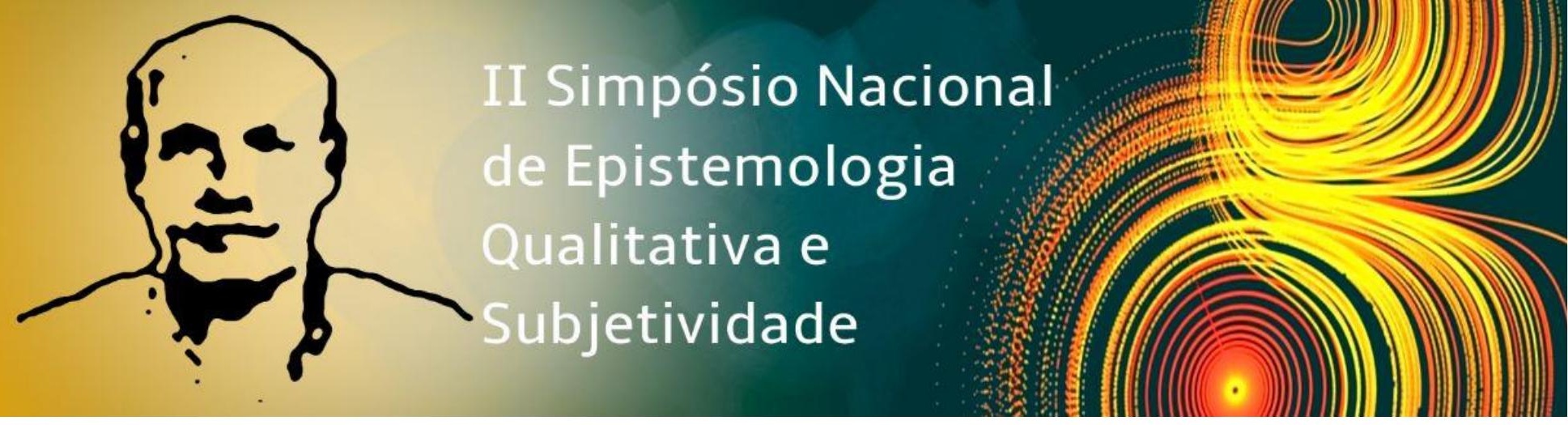

Eixo temático: A subjetividade na formação de professores e outros profissionais

\title{
Processos subjetivos de professores quanto ao não uso de tecnologias nas práticas
}

\section{docentes}

Lucicleide Araújo de Sousa Alves, SEEDF /UCB,

lucicleide.ead@gmail.com

\section{Resumo}

O objetivo de disseminação da cultura contemporânea por meio de cursos de formação nos âmbitos educativos, com foco na utilização das tecnologias nos processos de ensino e de aprendizagem, tem sido objeto de estudo e pesquisas, para o acompanhamento dos seus efeitos e das suas repercussões iniciados nos espaços de formação continuada e de sua aplicabilidade nos processos de ensino e aprendizagem. Este estudo teve por objetivo analisar as repercussões de ações de formação para o uso de Tecnologias Digitais de Informação e Comunicação (TDICs) nas subjetividades de professores das escolas públicas da educação básica do Distrito Federal. A sua base empírica foi o curso Proinfo Integrado ofertado, nos anos de 2013 e 2014, pela Diretoria de Mídias Educacionais e Conteúdos Digitais (DIMD) aos professores da rede pública do Distrito Federal. O curso faz parte do Programa Nacional de Formação Continuada em Tecnologia Educacional. A pesquisa oportunizou espaço para escuta in loco de 17 professores concluintes do curso, sobre o uso de tecnologias e o não uso nas práticas docentes. Apresentaremos os processos subjetivos produzidos por 5 professores quanto ao não uso das tecnologias nas práticas docentes e os elementos de sentido envolvidos. Trata-se de uma Pesquisa-ação (THIOLLENT, 2011). Metodologicamente, foram utilizados como técnicas de produção de dados e informações o questionário, a entrevista individual em profundidade com 17 professores in loco e a observação em sala de aula. Utilizamos o processo de análise de conteúdo baseado em Bardin (2002), inspirados em elementos da metodologia construtivo-interpretativo, segundo González Rey (2010). Os pressupostos da psicologia histórico-cultural, particularmente a noção de subjetividade na perspectiva da Psicologia Histórico-Cultural, particularmente no seu entendimento provido pelos estudos iniciados por Vigotski (2007) e ampliados por González Rey (2012, 2005), em diálogo com a Teoria da Complexidade (MORIN, 2007). Os estudos revelaram processos subjetivos, evidenciados por sofrimentos psíquicos quanto a tentativas de integrar, por parte dos professores, os recursos tecnológicos aos processos de ensino e de aprendizagem.

Palavras-chave: Formação de professores. Sentidos subjetivos. Tecnologias digitais de informação e comunicação. 


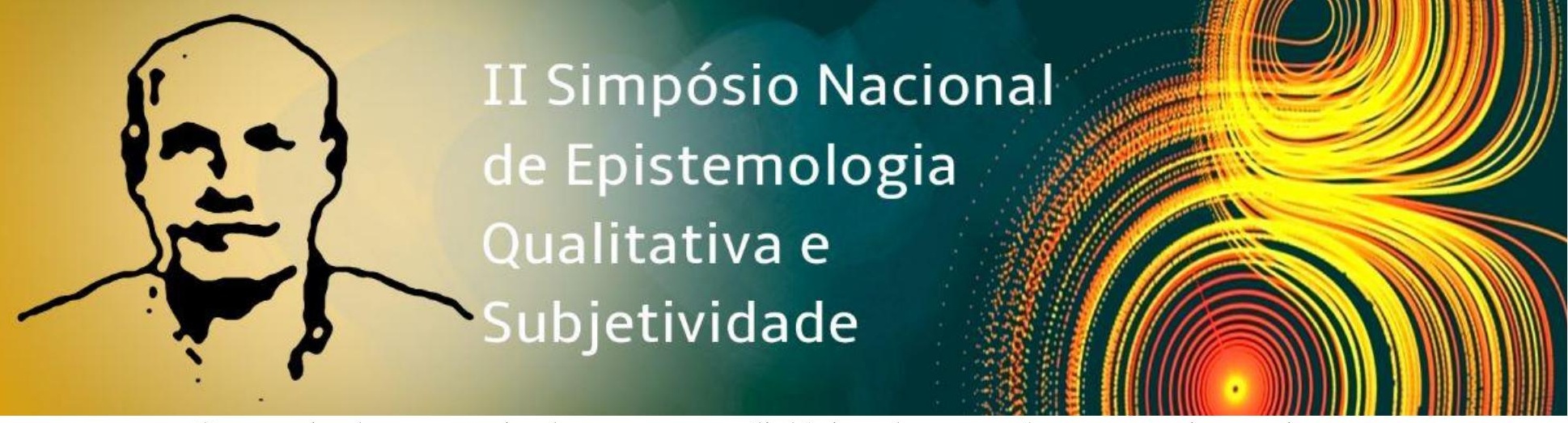

O pesquisador por meio de um espaço dialógico de escuta buscou sentir o universo afetivo, imaginário e cognitivo do outro, na tentativa de compreender suas atitudes e comportamentos, ideias, valores, símbolos e mitos, de modo profundo. Por isso, para a produção dos dados foram realizadas entrevistas individuais em profundidade com os professores, in loco. Configurando-se, desse modo, em análises heurísticas sobre os processos subjetivos quanto ao não uso de tecnologias nas práticas docentes, aos sentimentos envolvidos bem como as dificuldades e os seus desafios inerentes enfrentados pelos professores em diferenciados contextos educativos, após terem concluído o curso de formação "Proinfo Integrado" (MEC, 2017).

\section{Elementos de sentido envolvidos quanto ao não uso de tecnologias por professores nas práticas docentes}

O contexto escolar da rede pública de ensino do Distrito Federal não tem se apresentado como espaço tão favorável ao uso de tecnologias por parte dos professores com os estudantes. Até mesmo dois dos doze professores considerados "aptos", adeptos das tecnologias (Professor A, Professor B) e que se sentem seguros e com formação específica na área para utilizar os computadores instalados nos laboratórios de informática nas escolas como ferramenta pedagógica nos processos de ensino e de aprendizagem - disseram se sentir frustrados diante de tantas tentativas sem êxito. Alegam também as dificuldades, em função das condições, em termos de infraestrutura e de manutenção dos equipamentos dos laboratórios para o desenvolvimento das atividades com mais qualidade quando se conta com $\mathrm{o}$ apoio de tecnologias em rede, em complemento às atividades pedagógicas. (Professores $\mathrm{A}, \mathrm{e}$ B). Vejamos as suas manifestações:

"Bem, em primeiro lugar eu sou adepto às tecnologias como ferramenta do processo de aprendizagem. Mas eu tenho encontrado muita dificuldade nas escolas em que eu tenho passado da manutenção do laboratório de informática". "[...]Eu indico alguns softwares, algumas ferramentas que eles utilizam individualmente, mas com o coletivo, com a sala, infelizmente, eu ainda não tive êxito por mais que eu queira, por mais que eu tente, infelizmente diante dessa dificuldade eu não tenho usado. (Professor A).

A não utilização se dá pelo simples fato da falta de recursos. Só por isso. Então, assim, a escola ela tem um laboratório de informática que está desativado, então, a gente não tem como levar os alunos para esse laboratório para poder desenvolver algum tipo de atividade, alguma complementação, pesquisa, produção de vídeo, seja lá o que for. Não temos sinais de internet nas salas, então, por 


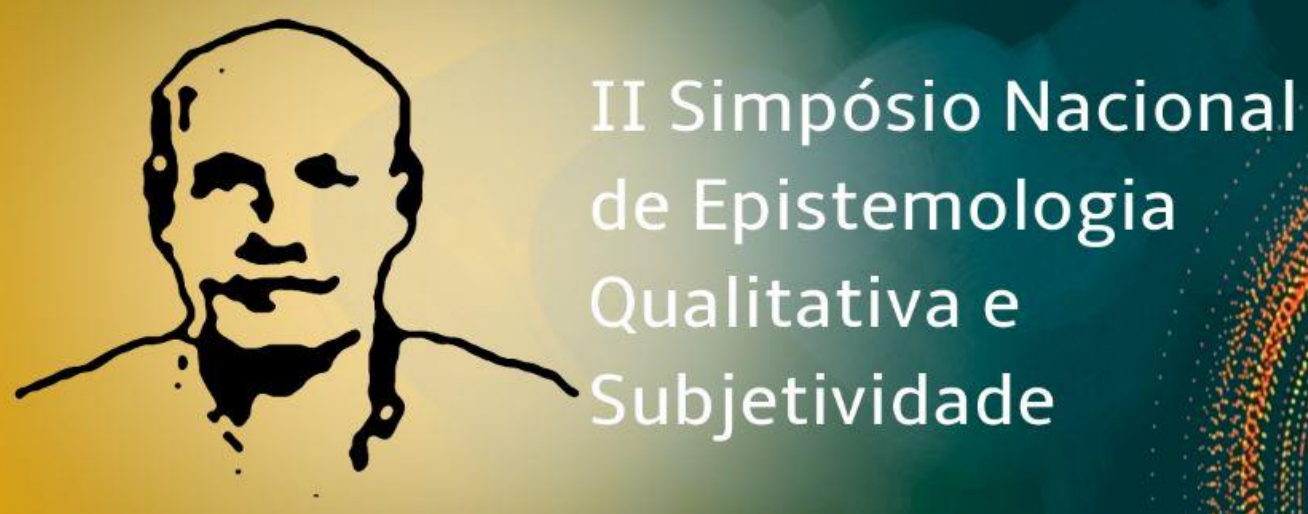

exemplo, o meu diário eletrônico eu atualizo ele em casa, não tem como atualizar na escola, ou então eu utilizo meu celular para poder fazer atualização do diário eletrônico. (Professor B).

Pelos excertos acima proferidos pelos professores, fica claro que o corpo docente tem encontrado muitas dificuldades no que diz respeito ao acesso aos computadores disponibilizados nos laboratórios e ao acesso à rede mundial de computadores (Internet).

Alguns professores chegam a passar, inclusive, constrangimentos no momento da execução da aula, conforme o terceiro depoimento proferido a seguir, pela professora $\mathrm{C}$, ao relatar sobre a dificuldade quanto ao acesso à Internet, que, consequentemente, inviabiliza a conclusão da atividade planejada, justamente pela falta de infraestrutura adequada nas escolas para os professores ousarem mais.

Então, nós temos uma certa dificuldade do acesso a Internet. Então assim, as vezes você imagina, já aconteceram algumas vezes de levar um aluno para o laboratório e a rede toda cai e você acaba não concluindo a tarefa proposta para aquele dia. E a parte de qualidade também, que às vezes deixa a desejar. E a parte de qualidade também, que às vezes deixa a desejar. Mas, mais mesmo a questão da Internet mesmo". "somente eu utilizando, e não os alunos, cada um na sua própria máquina".(Professor $\mathrm{C}$ ).

Vejamos mais alguns excertos que expressam as configurações de sentidos subjetivos envolvidos - quanto aos 5 professores, dos 17 entrevistados, que declararam não fazer uso de tecnologias, e os sentimentos produzidos por eles por não conseguirem fazer uso da tecnologia com os estudantes. Além disso, eles expressam também os motivos pelos quais não fazem uso das tecnologias nas práticas pedagógicas, apesar de terem feito o curso de formação, o qual tem como um dos seus objetivos a utilização das tecnologias na sala de aula, pedagogicamente.

"Na verdade eu fico angustiando, fico angustiado, porque eu como já disse sou adepto as tecnologias. Eu uso na minha preparação de aula, eu utilizo para desenvolver novos métodos, novas técnicas didáticas para atuar na sala de aula. $\underline{E}$ não consigo utilizar na prática, então eu fico extremamente angustiado e ansioso para que eu possa ter uma oportunidade de utilizar". (Professor A).

"Então, eu sinto que eu fico meio que de mãos atadas e tentando tirar coelho da cartola. Porque como você já observou, eu já fiz curso dessa área. Eu faço um trabalho como formador de professores de uma rede particular, onde eu trabalho justamente com metodologias ativas e a utilização de tecnologias no processo de 


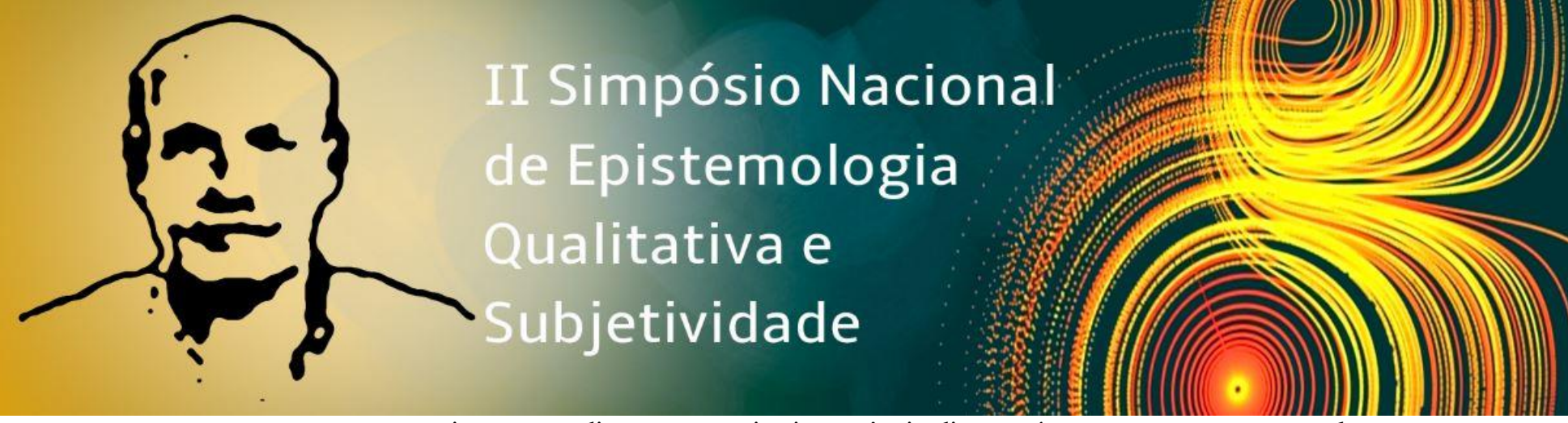

ensino e aprendizagem, eu sei a importância disso, até mesmo para tornar as aulas mais atrativas, mais interessantes para os alunos. [...] Então assim, eu sei exatamente a importância das tecnologias no processo educacional e eu fico de mãos atadas uma vez que na instituição que eu trabalho não tem esse recurso. $\mathrm{Na}$ escola em que eu estou mal a gente tem recarga, tinta para carregar pincel. Daqui a pouco, eu vou ter que dar aula ditando texto para os meninos, porque o livro não complementa, não tem recursos tecnológicos, não tem papel, não tem tinta para pincel, não tem tinta para impressora. Então assim, a gente tem que inovar o máximo, mas fica meio que de mãos atadas mesmo, me sentindo um pouco frustrado nesse sentido". (Professor B).

“Infelizmente a gente fica pra trás, a partir do momento que a gente não dá essa oportunidade pro aluno na escola de estarem tendo contato com todas essas tecnologias, todas essas ferramentas que hoje em dia está muito comum... é claro que eu sei que existem outros lugares que ainda não tem esse acesso todo, mas na nossa realidade aqui tem, então infelizmente os nossos alunos ficam pra trás em mais uma coisa, em mais um quesito na vida deles, eles estão pra trás, porque assim, infelizmente nem todos os alunos tem esse tipo de acesso em casa, o máximo ali é a TV, a TV aberta, e só, e músicas, músicas, mas exatamente a internet, a informática que eu acho que hoje é o que domina a tecnologia eu acho que é isso, nem todos tem, então a gente teria que oportunizar isso a eles aqui na escola, mas não tem como". (Professor D).

“[... me dá uma angústia e um sentimento assim de, de que a gente tá perdendo, primeiro, é recurso, que é empregado nesses cursos de formação, então é dinheiro que tá sendo investido que não, que a gente não tá tendo retorno, né? É, o recurso humano, é o nosso esforço pessoal de buscar esse, essa formação que não tá sendo aproveitado, e quem perde mais com isso são os nossos alunos porque cada vez mais a escola pública fica defasada em relação as instituições particulares, já provei esse acesso aí e hoje é praticamente natural um aluno de escola particular utilizar tablete e utilizar smartphone em sala de aula para acessar conteúdos e atividades do programa da escola, então, a gente vê o seguinte, é, é um recurso que tá sendo bem empregado, mais que aqui na ponta não tem como a gente aplicar, não tem como a gente dar essa devolutiva para sociedade, então é angustiante, eu resumo nessa palavra, a gente fica angustiado". (Professor E).

Pelas falas acima proferidas pelos professores e categorizadas, pudemos constatar que os sentimentos de angústia e de ansiedade (Professor A), a sensação de estar de mãos atadas (Professor B), de ficar para trás (Professora D), de angústia e perda (Professor E), todos expressos por meio da linguagem oral simbólica, emergem como elementos de produção de sentidos entre os professores entrevistados quando se referem ao não uso de tecnologias em sua rotina pedagógica, na vivência da docência.

É importante esclarecer que a produção de sentido é singular de cada sujeito. No entanto, podem ser identificados elementos de sentido comuns entre os professores: a frustração, elemento constitutivo da subjetividade social do coletivo. Referem-se às condições 


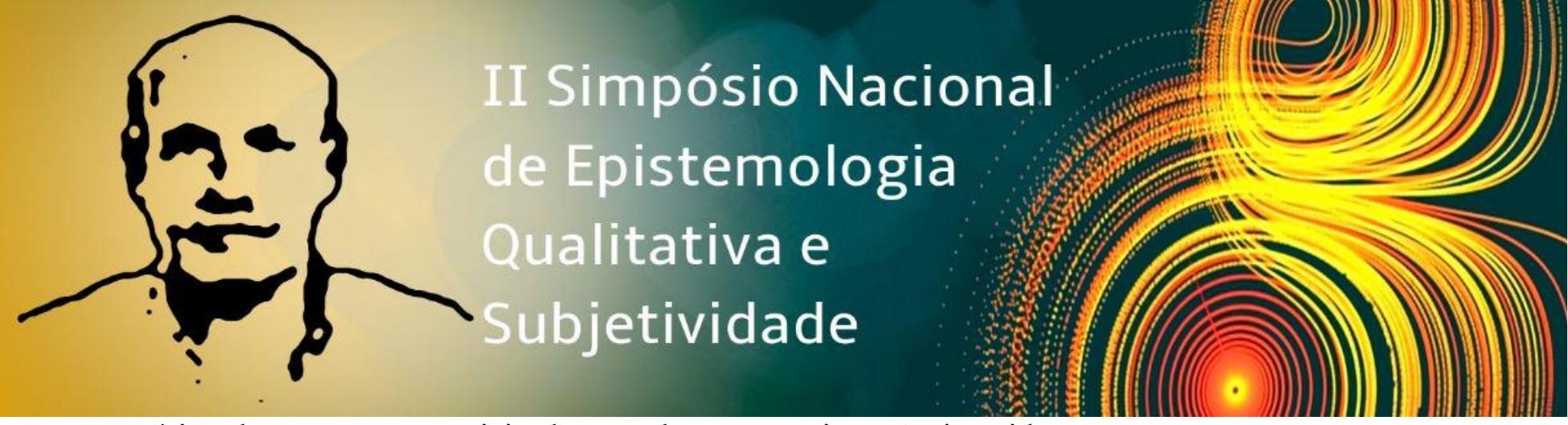

precárias dos contextos sociais das escolas nos quais estão inseridos e que se apresentam desfavoráveis para aliar o apreendido no curso de formação que fizeram com a prática cotidiana das salas de aula e os aspectos subjetivos implicados.

Esses sentidos subjetivos expressados por meio de uma síntese dos sentimentos já anteriormente vividos pelos professores atualizam-se pelos processos subjetivos sociais nos espaços e momentos nos quais a atividade docente acontece. Por exemplo, quando não conseguem aliar o que viram no curso com o que é possível de ser feito nos espaços escolares nos quais constroem a sua história de vida profissional.

Por meio também das falas acima proferidas pelos professores (A, B, D e E) foi possível constatar iniciativas, sem dúvidas, e tentativas, por exemplo, de uso da Internet, nos espaços dos laboratórios de informática, por meio de celulares em salas de aula como um recurso complementar aos trabalhos realizados nesses espaços. Todavia, as tentativas mostraram-se frustrantes em função de fatores limitantes e que pouco colabora para a continuidade do trabalho. Além de serem iniciativas pontuais e individualistas.

Ou seja, a falta de infraestrutura adequada dificulta e compromete o exercício do trabalho do(a) professor(a) com qualidade e o cumprimento do que fora planejado, pela impossibilidade do não cumprimento por parte dos alunos da tarefa proposta para aquele dia, uma vez que o recurso para tal tarefa requer o uso efetivo da Internet, conforme profere a Professora C. Bem como, as iniciativas de utilização das tecnologias pelos professores em contextos educativos pouco favoráveis, aliadas às frustrações produzidas, têm contribuído para a falta de "motivação" (BOCK, FURTADO e TEIXEIRA, 2008; 2011), gerando e/ou reforçando-se ainda mais a insegurança, o descrédito, o sentimento de desvalorização, a ansiedade e a angústia nos professores.

Diante de tantas tentativas frustradas, o(a) professor(a) acaba optando por somente ele(a) fazer uso da tecnologia, na preparação de suas aulas, como uma forma de colocar em prática o aprendido no curso e de possibilitar, ainda que se utilizando dos próprios recursos, o acesso dos estudantes aos instrumentos culturais tecnológicos de sua época. No entanto, como 


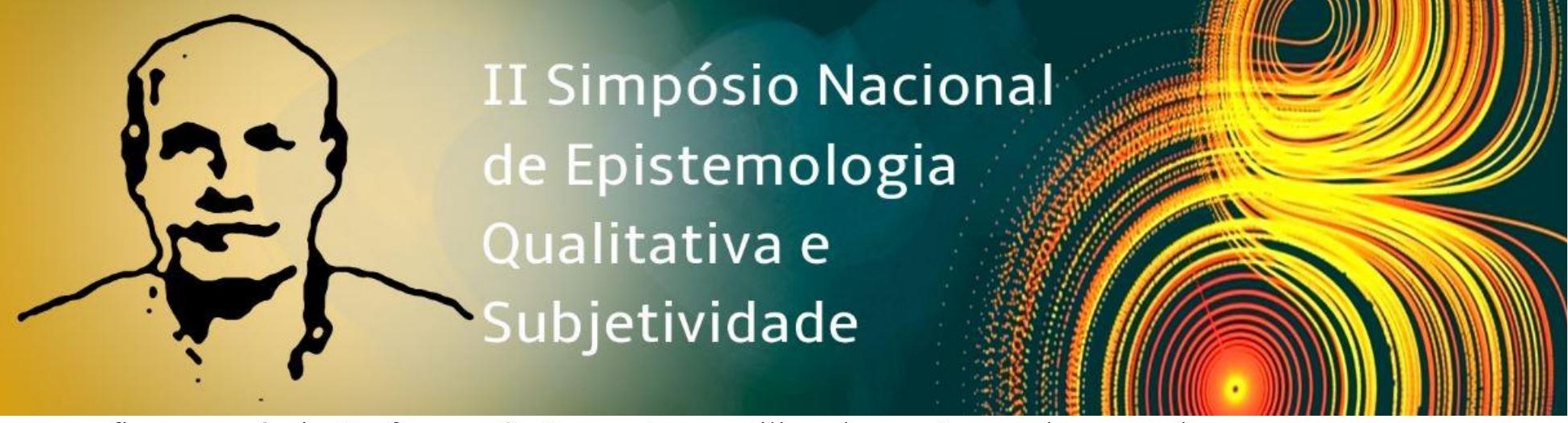

afirma a própria Professora C, "somente eu utilizando, e não os alunos, cada um na sua própria máquina”.

Dessa forma, as repercussões quanto ao uso de tecnologias na educação e os seus impactos ainda não ultrapassam o uso do recurso que está mais focado no ensino, ainda com pouca relevância e poucos impactos destas quanto à sua utilização nos processos de aprendizagem dos estudantes.

Todavia, do mesmo lugar que emergem os sentimentos como frustrações, angústias, tristezas, ressurgem também outros: como o desejo, a esperança, a força; sentimentos, esses, capazes de fazer emergir o sujeito subjetivo autor, nos interstícios entre a dinâmica que envolve a subjetividade individual e a social, em constante relação.

"Mas eu acredito que o ano que vem nós temos uma perspectiva de melhorar o laboratório [...]" (Professor A)

Para o ano que vem eu desejo conversar com o Gerente pra ver se a gente faz um evento maior, somente com essa abordagem. Várias oficinas, várias conversas, várias experiências só abordando essa temática. E aí eu vou propor a ele vê se a gente consegue fazer no âmbito da secretaria, no âmbito da DIMD um evento semelhante aquele simpósio, mas que, com esse enfoque específico, trazendo parceiros: a SaferNet, tem outras instituições que a gente tem pesquisado e que trabalham essa questão, inclusive, fora do país. [...] Então eu pretendo para o ano que vem elaborar ainda mais esse projeto e fazer uma coisa maior, entendeu? (Professor F)

A consciência em relação à fenda existente entre o ideal (uso dos recursos tecnológicos nas práticas docentes) e o real (escolas desprovidas de recursos) pode mobilizar ou imobilizar o sujeito do ensino a agir. Essa atitude associa-se às configurações subjetivas construídas por cada grupo, dentro de sua localidade. Assim, a cultura social constituída nos espaços formativos é determinante para a ocorrência dos avanços necessários dentro dos complexos espaços educativos e das redes de significados constituídas pelo corpo escolar, ou não.

Os espaços formativos, nessa perspectiva, são espaços também por onde perpassam as tramas ocultas de sentidos subjetivos produzidos pelos sujeitos pertencentes e atuantes em tais 


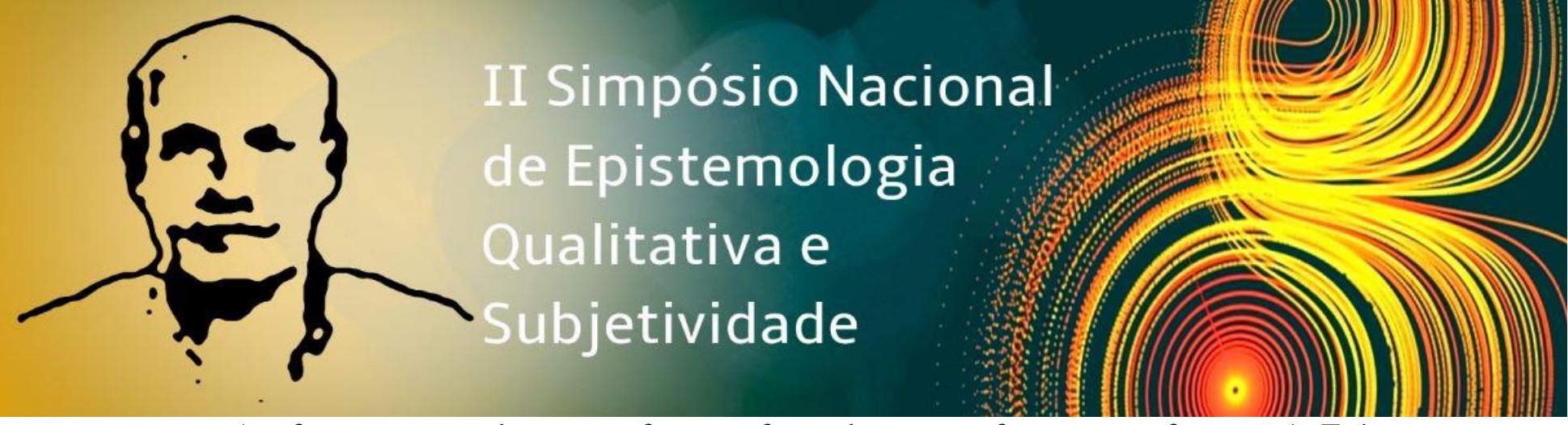

contextos (professores e estudantes, professores formadores e professores em formação). E é no entremeio dessas relações constituídas pelos protagonistas nessas redes sociais, face a face e/ou virtualmente, que sentidos subjetivos são desvelados e novos sentidos subjetivos produzidos, podendo, desse modo, ressignificar a rede ou paralisá-la. Isso vai depender da qualidade do envolvimento dos sujeitos quando o problema é instaurado na localidade contextual em que se inserem e atuam.

González (2012, p.135) assegura que “o sentido subjetivo expressa a condição vital das pessoas". Os sentidos subjetivos produzidos integram, ao mesmo tempo, os processos simbólicos e os emocionais. Da razão e da emoção, da prosa e da poesia. Eles são produzidos e expressos na atividade profissional. Por um lado, sendo pressionados a inovarem as suas práticas, que já não mais correspondem à realidade contemporânea; e, por outro, impactados com a impossibilidade de não corresponderem, sentindo-se inseguros, com medo, por não saberem como fazer, por estarem diante de uma realidade educativa que muito mais os limitam do que lhes possibilitam transformações, dificultando-lhes a atuação como agentes transformadores. Ao mesmo tempo, buscam saídas para reverter o caos em algo produtivo, alimentados pela esperança de que algo possa acontecer, deslocando o fazer que deveria ocorrer no presente para o futuro próximo.

As narrativas proferidas pelos professores A, B, C, D, E e F - expressam as "produções de sentidos" (GONZÁLEZ REY, 2012) produzidos por cada um dos sujeitos em tempos e espaços diferenciados de vida coletiva e singular. Elas são expressões das histórias singulares e locais em que esses sujeitos exercem o ser e o seu fazer pedagógico. Representam a cultura das localidades nas quais esses sujeitos estão se fazendo e constantemente se refazendo. São articuladas com configurações passadas e atuais de professores que viveram e vivem num determinado contexto e que compartilharam vivências de experiências que já não mais atendem à realidade daquela localidade, daquelas gerações, que estão permanentemente em constituição e atualmente baseadas em uma nova condição de vida impulsionada por tecnologias mais sofisticadas em relação às gerações anteriores.

Todavia, os sentidos subjetivos produzidos não são determinantes e nem determinados por meio de uma única atividade. Esses são processos já constituídos por professores em

\section{BRASÍLIA, 22 a 25 DE OUTUBRO DE 2019 CENTRO UNIVERSITÁRIO DE BRASÍLIA - UNICEUB}




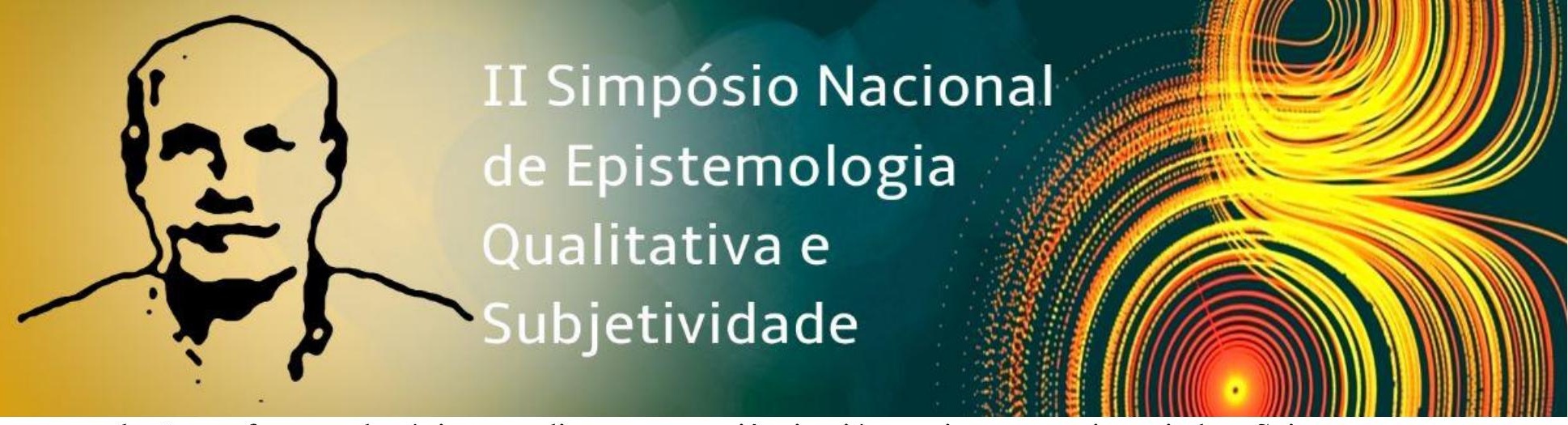

relação ao fazer pedagógico em diversas experiências já anteriormente vivenciadas. Seja por meio de intenções individuais ou grupais, as produções de sentidos emergem e podem atuar como novos mobilizadores para a produção de novos sentidos subjetivos com base nos já produzidos, bem como podem atuar como fontes imobilizadoras e de controle e regulação, pois requerem sempre ações, agir, por parte dos sujeitos, para reconfigurar novos cenários para a produção de outros novos sentidos subjetivos, com autoria.

Em contextos escolares e de formação iniciada e/ou continuada, são requeridas dos sujeitos ações coletivas, e não individuais, para que em conjunto, professores e equipe diretiva, professores em formação e formadores possam reconfigurar novos processos subjetivos, a fim de que a dinâmica dos trabalhos pedagógicos possa fluir com condições adequadas à realidade contextualizada, com obtenção de uma melhor qualidade nos processos tanto de ensino quanto nos de aprendizagem.

Assim, a construção de tramas ocultas a serem significadas por sentidos subjetivos atribuídos pelos sujeitos na ação requer a necessidade de construção de espaços dialógicos para compartilhamentos dessas configurações subjetivas para uma maior consciência dessas produções e para os professores refletirem e se reposicionarem em relação aos processos de sentidos subjetivos configurados.

A angústia, a frustração, a consciência, a alegria, são emoções não da ordem do discurso, mas do já vivido pelos professores, pois não há o que se dizer sobre o que não se viveu. Assim, no exercício da prática docente, nos momentos em que se tencionam a teoria com a prática cotidiana, é que se pode enxergar processos subjetivos já vivenciados em outras circunstâncias, e tomar consciência da situação para reelaborações de novos processos de sentidos subjetivos que permitam redirecionamentos e vivências por meio de outras novas rotas.

Por isso a necessidade de espaços de construção dialógica coletiva, para que o problema, os sentidos subjetivos pertencentes sociais daquele grupo sejam evidenciados e em coletivo sejam tomadas as possíveis providências, construindo circunstâncias favoráveis para que aquele grupo evolua, desenvolva-se e consiga produzir sentidos subjetivos atuais, sem, 


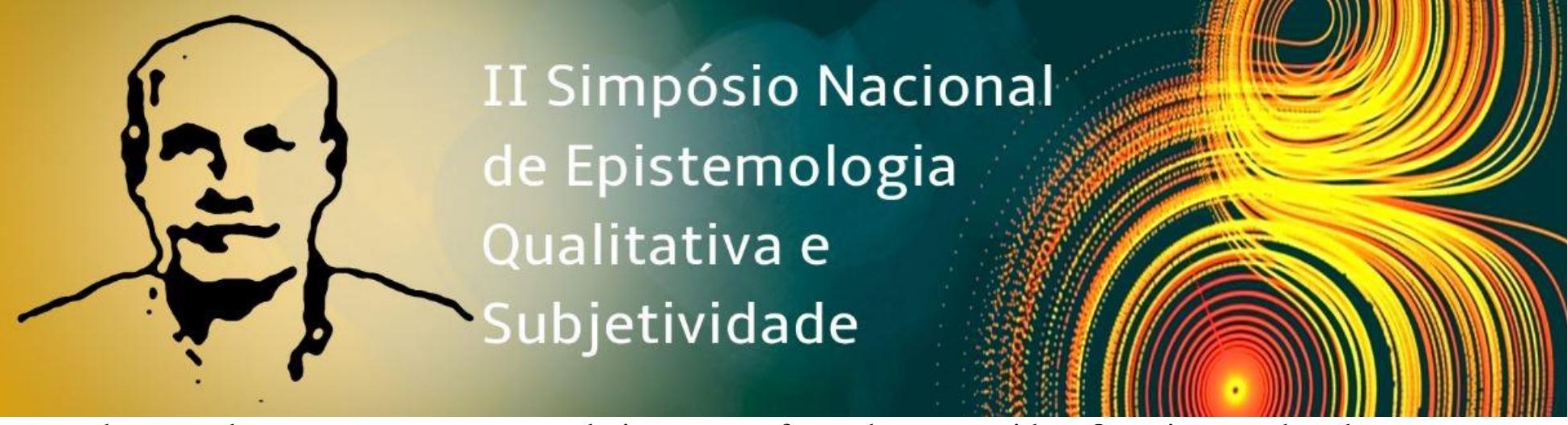

desse modo, negar os processos evolutivos e transformadores ocorridos. Ou seja, a quebra de paradigmas é necessária para a possibilidade de se pensar a realidade sobre novas percepções e de acordo com o mundo contemporâneo.

É preciso tensionar os espaços, para se compreender o que se encontra oculto, os nós das tramas que impedem os professores de caminharem rumo a novas configurações de processos apoiados em tecnologias, para evitar o imobilismo, a paralisia, e propiciar os avanços necessários à educação. Por isso a necessidade de um pensamento complexo, para que os novos sentidos subjetivos produzidos possam ressignificar novos processos, novos espaços, e possibilitar o desenvolvimento das subjetividades presentes em suas mais diversas localidades da vida social; e a sociedade, a educação ascender, recolocando-se em ação por meio de uma autonomia relativa a partir de autorias subjetivas, protagonizadoras de novos sentidos subjetivos.

Nesse sentido, os cursos de formação atuam como instrumentos potenciais para o despertar de consciência e a produção em coletivo de novos sentidos subjetivos. A partir do momento em que os sujeitos são colocados diante da cultura e delas se apropriam e reconhecem os seus potenciais, novos processos subjetivos são constituídos e dessas intencionalidades subjacentes novas são reconfiguradas, a fim de que, diante de experiências frustrantes, estas possam ser ressignificadas no presente, a partir do já produzido e vivido em experiências passadas, com perspectivas do futuro, com ações no presente.

\section{Concluindo...}

As configurações subjetivas produzidas socialmente e arraigadas sobre uma determinada cultura só serão passíveis de sofrer os seus avanços por meio da formação e da abertura de espaços de diálogos que possibilitem gerar novas representações pelos sujeitos da práxis pedagógica.

Dessa forma, a construção de espaços de dialogicidades representa uma das vias capazes para a produção de sentidos, de modo a colocar os sujeitos em constantes 


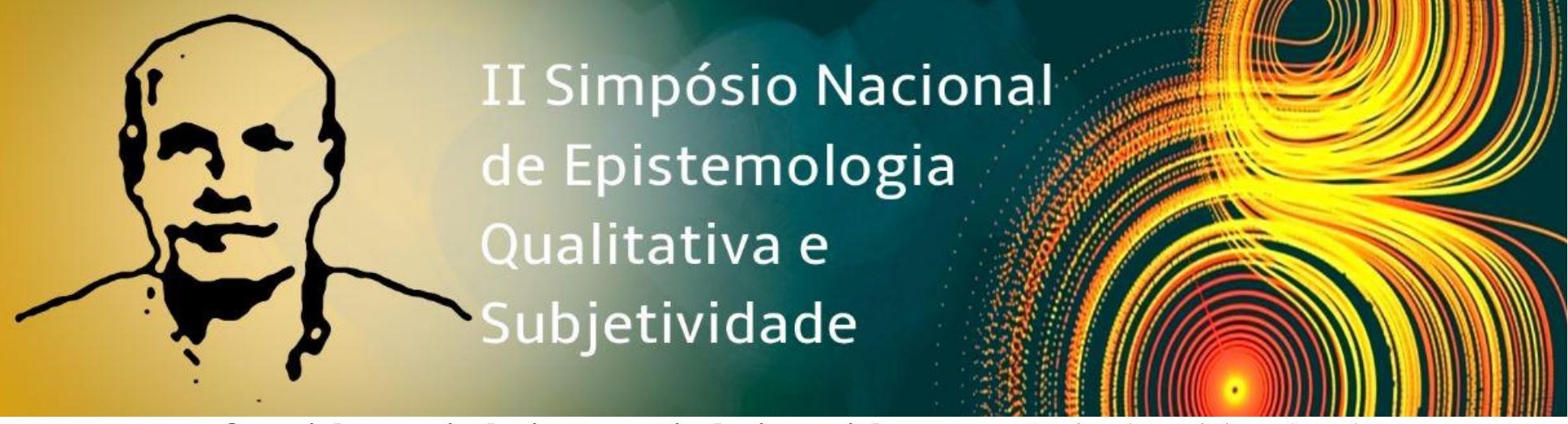

- O social na psicologia e a psicologia social: a emergência do sujeito. 3. ed.

Petrópolis, RJ: Vozes, 2012.

MORIN, Edgar. Introdução ao pensamento complexo. Porto Alegre: Sulina, 2007.

MEC. Proinfo Integrado. Recuperado de http://portal.mec.gov.br/escola-de-gestores-daeducacao-basica/271-programas-e-acoes-1921564125/seed-1182001145/13156-proinfo-

integrado, em 25 jun. De 2017.

THIOLLENT, Michel.. Metodologia da pesquisa-ação. São Paulo: Cortez, 2011.

VIGOTSKI, Lev Semenovich. A formação social da mente. 7. Ed. São Paulo: Martins Fontes, 2007. 